КЛЕАНДРОВ Михаил Иванович

доктор юридических наук, член-корреспондент РАН, главный научный сотрудник Института государства и права РАН

\title{
О ПРАВОВОМ РЕГУЛИРОВАНИИ ОТНОШЕНИЙ В СФЕРЕ “ЗЕЛЕНОЙ” ЭКОНОМИКИ ПРИ КОРОНАВИРУСНОЙ ПАНДЕМИИ 2020 Г.*
}

Рассматривается проблематика особенностей правового регулирования общественных отношений в сфере “зеленой” экономики в экстремальных условиях коронавирусной пандемии 2020 г. Отмечается, что эта пандемия - очередная в ряду иных пандемий, и наверняка не последняя, а посему общее - экстремальное - правовое регулирование общественных отношений, в том числе в сфере “зеленой” экономики, должно предусматривать и могущие возникнуть будущие катастрофьы эпидемиологического характера, отрицательно и масштабно воздействующие на экономику. Пока же делается вывод в статье, сколь-нибудь эффективных законодательно-нормативных актов экстремального характера, обеспечивающих устойчивость “зеленой” экономики в условиях коронавирусной пандемии, не принято. Вносятся предложения, направленные на решение этой проблемы.

Ключевые слова: “зеленая” экономика, коронавирусная пандемия, экстремальное правотворчество.

\section{KLEANDROV Mikhail Ivanovich}

Ph.D. in Law, corresponding member of RAS, chief researcher of the Institute of State and Law of RAS

\section{ON THE LEGAL REGULATION OF RELATIONS IN THE FIELD OF “GREEN" ECONOMY IN THE CORONAVIRUS PANDEMIC OF 2020*}

The article deals with the problems of legal regulation of public relations in the field of "green" economy in the extreme conditions of the coronavirus pandemic in 2020. It is noted that this pandemic is another in a series of other pandemics, and certainly not the last, and therefore the general - extreme - legal regulation of public relations, including in the field of "green" economy, should also provide for future catastrophes of an epidemiological nature that may occur, negatively and on a large scale affecting the economy. In the meantime, the article concludes that no effective legislative and regulatory acts of an extreme nature have been adopted to ensure the sustainability of the "green" economy in the context of the coronavirus pandemic. Proposals are being made to address this problem.

Keywords: "green" economy, coronavirus pandemic, extreme law-making.

Положение дел в экономике нашей страны (да и за рубежом - практически в той же степени) из-за коронавирусной пандемии не могло не ухудшиться. Выступая на Совещании по вопросам развития энергетики 29 апреля 2020 г. (прямую трансляцию вел телеканал «Россия-24»), Президент РФ В.В. Путин отметил, что коронавирус также повдиял на экономику и ТЭК, и эти проблемы носят системный характер и выходят далеко за национальные границы; в частности, распространение коронавируса и ограничительные меры снизили темпы мирового экономического развития, сократили мировой ВВП.

Естественно, что ситуация с экологическими правонарушениями в ходе и по завершению коронавирусной пандемии 2020 г., как в нашей стране, так и за рубежом - в промышленно развитых государствах - не может не обостриться. Деятельность предприятий многих отраслей промышленного производства, в том числе (а скорее - прежде всего) входящих в топливно-энергетический комплекс, где особенно значима «зеленая» энергетика, экологические загрязнения которыми окружающей среды на время острой фазы пандемии была приостановлена, на фазе ее затухания и, тем более, после ее завершения, резко ускоряются в своем производстве. Падение уровня производства вызвало сокращение доходов, а то и прямые убытки. Как отмечается в СМИ (со ссылкой на данные аудиторско-консалтинговой компании «ФинЭкспертиза»), совокупная прибыль российского бизнеса по итогам пяти месяцев этого года сократилась на 67\% в годовом исчислении; в итоге, более трети компаний получили убытки. При этом основным генератором убытков за этот период оказалась оптовая торговля природным газом ${ }^{1}$. Экспорт тру-

* Исследование выполнено при финансовой поддержке РФФИ в рамках научного проекта № 20-011-00270 «а».

1 См.: Соловьева О. Коронавирус спровоцировал новый инвестиционный спад // Независимая газета. 2020, 24 августа. бопроводного газа из России в первой половине 2020 г. сократился на 16,7\% (до 98,2 млрд кубометров) по сравнению с тем же периодом 2019 г. ${ }^{2}$

А поскольку за время «простоя» либо серьезного ограничения своего функционирования у них серьезно сократились доходы, подчас до критического уровня, им - и это в очень широких масштабах - приходится форсировать темпы производственной деятельности. Что само по себе не может не отразиться на объемах экологического загрязнения окружающей среды. А в тех - технологических - случаях, когда технические, организационные и правовые ограничения, обусловленные требованиями экологической безопасности, препятствовали резкому росту промышленного производства (если не у всех, то - у многих) предприятий, то ими можно не сомневаться - стали элементарно пренебрегать.

Скажется это, к счастью, не сразу - за время пандемии и, соответственно - вынужденной приостановки (дибо сокращения масштабов) производства экодогическая обстановка в атмосфере, в водных бассейнах и пр. - серьезно улучшилась.

Но очевидно - это улучшение вскоре сменится резким ухудшением. Готово ли к такому развороту событий наше природоохранное законодательство, наш совокупный организационно-правовой механизм обеспечения экологической безопасности и его правоприменительная практика, вся наша «зеленая» экономика?

Сдается, что нет. Наша страна к этому оказалась не готова организационно: например, в «закромах» Госрезерва, что общеизвестно, при начале эпидемии (стремительно переходящей в пандемию) не оказалось ни противоэпидемиологических масок, ни перчаток, ни необходимого медицинского оборудования. При этом также известно, что номенклатуру закладываемого на хранение имущества определяет не сам

2 См.: Тихонов С. Холодный расчет // Российская газета. 2020, 2 сентября. 
Госрезерв, а федеральные ведомства в соответствии со сферами своей деятельности.

Не готова оказалась страна и с точки зрения законодательного регулирования - законотворческий процесс оказался весьма длительным и к экстремальным условиям вообще, как и к коронавирусной пандемии, в частности, оказался не приспособленным.

Так, не была «задействована» ст. 56 Конституции РФ, где в первых двух частях провозглашено: «1. В условиях чрезвычайного положения дия обеспечения безопасности граждан и защиты конституционного строя в соответствии с федеральным конституционным законом могут устанавдиваться отдельные ограничения прав и свобод с указанием пределов и срока их действия. 2. Чрезвычайное положение на всей территории Российской Федерации и в ее отдельных местностях может вводиться при наличии обстоятельств и в порядке, установленных федерадьным конституционным законом». Были объективные основания для того, чтобы эти конституционные положения задействовать? По факту - да, а с сугубо юридической точки зрения - не факт. Проблема, как представляется, заключалась в том, что в Федеральном законе от 21 декабря 1994 г. № 68-Ф3 «О защите населения и территорий от чрезвычайных ситуаций природного и техногенного характера» ${ }^{3}$ (с большим количеством изменений и дополнений) в качестве предмета его регулирования - в ч 1 ст. 1 - было указано: «катастрофа», что не подразумевало пандемию. Подтверждением чему служит дополнение в этот пункт Закона 2004 г., произведенное ст. 2 Федерадьного закона от 1 апреля 2020 г. № 98-Ф3 «О внесении изменений в отдельные законодательные акты Российской Федерации по вопросам предупреждения и диквидации чрезвычайных ситуаций» ${ }^{4}$ где после слова «катастрофы» было сказано: «распространение заболевания, представляющего опасность для окружающих». А это означает, что более четверти века пандемия и, тем более, эпидемия не признавадись обстоятельством чрезвычайной ситуации, и закрепленные в Законе от 21 декабря 1994 г. (а ведь в него было внесено с тех пор немало дополнений) меры не применялись.

Следует - в рамках исследуемой в настоящей работе проблемы - отметить, что в целом правовое регулирование отношений, охватывающих почти все сферы жизнедеятельности общества, в период коронавирусной пандемии было - по объему и количественным показателям - весьма обширным. На международном уровне стоит отметить Распоряжение Евразийского межправительственного совета от 10 апреля 2020 г. № 6 «О предпринимаемых в рамках Евразийского экономического союза мерах, направленных на обеспечение экономической стабильности в условиях развития пандемии коронавирусной инфекции COVID-19» ${ }^{5}$.

Что касается нашего национального законодательства, то Н.Н. Черногором и М.В. Задоило подсчитано: общее число принятых только на федеральном уровне актов в связи с противодействием распространению новой коронавирусной инфекции (COVID-19) к настоящему времени составляет 855 документов, включая 388 нормативных правовых актов и 451 документ рекомендательного и информационного характера Среди этих документов - 25 федерадьных законов, 16 указов Президента РФ, 119 постановлений Правительства РФ. Принятые нормативные правовые акты направлены на совершенствование раздичных элементов административно-правовых режимов, применяемых для минимизации негативных последствий чрезвычайных ситуаций; поэтапное установление и определение особенностей снятия ограничений и запретов в целях обеспечения санитарно-эпидемиологического благополучия населения; совершенствование медицинской деятельности, а также обеспечение лекарственными средствами и медицинскими изделиями; предоставление государственной поддержки физическим лицам, организациям и инди-

3 СЗ РФ. 1994. № 35, ст. 3648.

4 См.: Российская газета. 2020, 3 апреля.

5 См.: Официальный сайт Евразийского экономического союза. [Электронный ресурс]. - Режим доступа: http://www.eaeunion. org.16.04.2020 г. видуальным предпринимателям; определение особенностей корпоративных отношений; совершенствование механизмов функционирования бюджетной системы РФ; регламентацию особенностей осуществления образовательной деятельности. В связи с чем ими даже сделан вывод: кризисные явления в жизни общества и государства меняют представления о праве и правовом регулировании, обусловливают изменение композиции правового пространства, в котором появдяются неизвестные традиционной юридической науке явления и феномены. Таким новым феноменом является вируспруденция - процесс правового опосредования мер по противодействию распространению новой коронавирусной инфекции (COVID-19) и принимаемые в результате нормативные правовые акты, затрагивающие самые разные сферы общественных отношений. Эти акты образуют нормативный правовой массив, который по своим характеристикам и внешним признакам тяготеет к циклическим массивам ${ }^{6}$.

Вместе с тем, несмотря на то что последствия коронавирусной пандемии, отрицательно сказываясь на экономике (ее показателях в раздичных отраслях), не могут не сказываться и сразу, и в более-менее отдаленных последствиях - на ее «зеленом» секторе, в названных законодательных и иных нормативных правовых актах хоть какое-то регулирование аспектов «зеленой» экономики обнаружить автору не удалось.

В самых свежих научно-правовых публикациях о правовом регулировании в период коронавирусной пандемии внимание проблематике особенностей регулирования в этот период «зеленой» экономике также не обнаружено 7 .

Правда, не удалось зафиксировать наличие внимания к проблематике «зеленой» экономики и со стороны юридической науки в работах, посвященных правовому регулированию экономической деятельности в особых правовых (до периода коронавирусной пандемии) режимах ${ }^{8}$.

Но ведь очевидно - последствиями нынешней коронавирусной пандемии, как и - не дай Бог - иных крупномасштабных катастроф природного и (или) техногенного характера обязательно стали (и - станут) самые раздичные ограничения: в производственной деятельности хозяйствующих субъектов; нарушения, а то и полный разрыв в цепочках хозяйственных связей; деформация механизма управленческих решений; проблемы в кредитно-финансовой сфере; проблемы в кадровой сфере и т.д. А главное - в неизбежном несоблюдении соответствующих норм экологического законодатедьства. И в этих обстоятельствах наверняка намеченные ранее меры по «озеленению» конкретных отраслей (сегментов) экономики окажутся либо официально заблокированы, либо до их выполнения попросту «не дойдут руки».

Еще недавно, но до коронавирусной пандемии 2020 г. С.А. Богодюбов в § 1 «Правовое воздействие на конкуренцию экономики и экологии» главы 10 «Экономическая деятельность и экология» коляективной монографии ${ }^{9}$ писал: «Подводя итог сказанному, можно констатировать неизбежность конкуренции экономики и экологии, приводящей к неотвратимости их взаимного сочетания, внедрению «зеленой экономики», экологизации правового, общественного, экономического и государственного аспектов жизни; правовые средства регулирования их соотношения, предусмотренные в законодательстве, весьма широки и развиты, но нуждаются

6 Черногор Н.Н., Залоило М.В. Метаморфозы права и вызовы юридической науке в условиях пандемии коронавируса // Журнал российского права. 2020. № 7.

7 См., в частности: Мельников В.Ю. Российское законодательство в период пандемии коронавирусной инфекции COVID-19 // Pocсийский судья. 2020. № 8. С. 12-18; Романовский Г.Б. 2019-nCoV как гибридная угроза системе прав человека // Конституционное и муниципальное право. 2020. № 7.

8 См., в частности: Мохов А.А. Ограничение прав юридических лиц и индивидуальных предпринимателей при чрезвычайных ситуациях // Юрист. 2013. № 6. С. 3-7; Он же: О концепции правового регулирования экономической деятельности в условиях особых правовых режимов: постановка проблемы // Юрист. 2014. № 4. C. 21-24.

9 См.: Право и экономическая деятельность: современные вызовы: Монография / Отв. ред. А.В. Габов. М.: «ИЗиСП», «Статут», 2015. 
в ускоренном внедрении; успехи экономизации экологии и экологизации экономики определяются уровнем их включенности в планы, ход и итоги социально-экономического развития страны; в конечном счете, может наступить момент, когда благополучие и достойная жизнь будут определяться не тодько и не стодько экономическими, сколько экологическими показателями».

Суровые жизненные реалии пандемии 2020 г. внесли серьезные коррективы в сказанное С.А. Боголюбовым. А ведь нельзя сказать, что сказанное им (процитированное здесь) - завышенные или оторванные от жизни ожидания. Сказанное - объективно верно, но в условиях нормальной, не экстремальной, даже не турбулентной жизнедеятельности общества. Просто сегодня сказанное им выгдядит издишне оптимистичным.

Но и общую - сегодняшнюю - ситуацию в сфере экологических отношений совсем удручающей назвать нельзя Подтверждением чему может послужить судебная практика В частности, рассматривая жалобу на решения нижестоящих арбитражно-судебных инстанций по спору об исчислении размера возмещения за нанесение вреда экосистеме из-за раздива нефти на 11-ти кв. км леса в Ханты-Мансийском автономном округе, Судебная коллегия по экономическим спорам Верховного Суда РФ своим Определением ${ }^{10}$ отменила судебные акты нижестоящих судебных инстанций и направила дело на повторное рассмотрение в первую инстанцию. По мнению Экономколлегии Верховного Суда РФ (со ссылкой на Постановление Конституционного Суда РФ от 2 июня 2015 г. № 12-П), ущерб должен быть возмещен не только в части причинения экологического вреда раздивом нефти лесу, но и остальным компонентам экосистемы, в данном случае - среде обитания беспозвоночных: «Возмещение вреда одному компоненту окружающей среды не заменяет исполнения обязанности по компенсации вреда другим компонентам».

В одном из развернутых прогнозов в парадигме четвертого энергетического перехода с развитием возобновдяемых источников энергии и низкоуглеродных технологий (первый, второй и третий переходы приходидись на уголь, нефть и газ), представленных в конце апреля 2020 г. Центром энергетики Московской школы управления «Сколково», будущее определялось, в числе иных векторов, как «баланс экологии и экономики (сбалансированная энергосистема благодаря всесторонней оценке применения источников энергии, включая затраты на рекультивацию, изъятие земель, инфраструктуру и т.д. с минимальным ущербом для окружающей среды и обеспечением устойчивого развития экономики)» ${ }^{11}$.

В то же время еще на состоявшейся в конце апреля 2020 г. в информационном агентстве ТАСС конференции на тему «Что такое возобновляемая энергетика сегодня и что будет через 15 лет» отмечалось, что именно в период кризисов происходит шоковое падение выбросов $\mathrm{CO}_{2}$, а после окончания кризиса - шоковое увеличение выбросов, и главной проблемой на сегодня является программа поддержки возобновляемых источников энергии ${ }^{12}$.

Те угрозы экологической безопасности, которые были названы в Стратегии экологической безопасности в Российской Федерации, утвержденной Указом Президента РФ от 19 апреля 2017 г. № $176^{13}$,где было отмечено, в частности, что окружающая среда в городах и на прилегающих к ним территориях, где проживает 74\% населения страны, подвергается существенному негативному воздействию, источниками

10 См.: Определение № 304-ЭС20-737 по делу А-75-474/2019 от 23 июля 2020 г.

11 Жизнин С., Черечукин А. Новый этап конкуренции энергоносителей. Неизбежность перехода на зеленые технологии не исключает использование твердого ископаемого топлива // Независимая газета - энергия. 2020, 9 июня.

12 См.: Никифоров О. Альтернативные источники энергии в постпандемический период. Перспективы развития ВИЭ в России: мнение производителей // Там же.

13 См.: Официальный интернет-портал правовой информации. [Электронный pecypc]. - Режим доступа: http:/pravo.gov.ru. 20.04.2017 г. которого являются объекты промышленности, энергетики, транспорта, капитального строительства, никуда не делись и после затухания пика коронавирусной пандемии. А в диссертационном исследовании Е.В. Чуличковой ${ }^{14}$ обращено внимание на то, что увеличивается число обращений граждан по поводу шума (более 57\% жалоб), электромагнитного излучения, плохого качества питьевой воды, продуктов питания, отсутствия благоустройства территорий (вывоз мусора, озеленение и т.п.), что процессами деградации охвачено более $40 \%$ всей площади сельскохозяйственных угодий России (что связано, в том числе, с отсутствием надлежащего правового регулирования антропогенной нагрузки и мер по сохранению земель, территориального землеустройства, научно-технического обеспечения сельского хозяйства), что ежегодно экономические потери из-за ухудшения качества окружающей среды, без учета вреда здоровью людей, составляют 4-6\% валового внутреннего продукта и т.д.

И устранение всех оснований ухудшения окружающей среды, отмеченных выше (как, разумеется, и не названных здесь) - одно из направлений развития «зеленой» экономики. В СМИ отмечается, что «коронавирус заставил правительства разных стран перейти к многомилдиардному стимулированию экономик. Исследование показывало: ЕС, Южная Корея, Канада, Бразилия, Норвегия, Китай и другие государства увязывают антикризисные меры с целями низкоуглеродного «зеленого» развития»» ${ }^{15}$. Вместе с тем здесь же указано: «В России этого пока не обнаруживается, хотя с каждым днем в мире все больше свидетельств необходимости переосмысления программы господдержки ее экономики в пользу экологической устойчивости».

Значительную, если не определяющую роль в «озеленении» нашей экономики признано сыграть адекватное законодательно-нормативное регулирование. Ему же должна предшествовать и, одновременно, определять вектор и методику этого «зеленого» правового регулирования соответствующая корректировка Основ государственной политики в области экологического развития Российской Федерации на период до 2030 г., утвержденной Указом Президента РФ от 30 апреля 2012 г. ${ }^{16}$

В процессе коррекции этого подитико-правового документа хорошо бы жестко и однозначно опредедить систему показателей, характеризующих качество окружающей среды, в том числе - в спектре радиочастотных природных ресурсов ${ }^{17}$, зафиксировать: необходимость углеродной маркировки товаров; целесообразность (и даже необходимость) экострахования в широком спектре предпринимательских отношений; целесообразность введения в нашей стране - в конкретных объемах - углеродного налога (в ЕС он будет введен с 2025 г.); вменение в обязанности банкрота взять на себя созданный им экологический ущерб и т.д.

Еще в 2009 г. Конституционный Суд РФ в Постановлении от 14 мая 2009 г. № 8-П провозгласил: «Правовые основы государственной подитики в этой сфере - исходя из того, что ценность сохранения природы и окружающей среды утверждается на конституционном уровне, - должны определяться таким образом, чтобы через реализацию указанной конституционной обязанности, имеющей всеобий характер, при решении социально-экономических задач обеспечивался баланс интересов субъектов хозяйственной и иной

14 См.: Чуличкова Е.В. Конституционно-правовой механизм обеспечения права каждого на благоприятную окружающую среду в Российской Федерации. Автореф. ... канд. юрид. наук. Екатеринбург, 2018 г. (научный рук-ль - проф. А.Н. Кокотов, судья Конституционного Суда РФ).

15 Уразова И. Субсидии украсили зеленым // Коммерсант. 2020, 13 августа.

16 Доступ на СПС «КонсультантПлюс».

17 В юридической литературе признается, что экологизация судебных споров, касающихся пользования радиочастотными природными ресурсами, по крайней мере в плане правопонимания, - вопрос принципиальный для экологического права и для интер-экоправа. - См.: Высторобец Е.А. Экологизация судебных споров, касающихся пользования радиочастотными природными ресурсами // Российское правосудие. 2015. № 6 (110), с. 110. 
деятельности, связанной с воздействием на окружающую среду, и интересов человека и общества в целом, и гарантировались соблюдение и защита экологических прав граждан. Этим предопределяются воздожение на государство в лице его органов соответствующих координационных, контрольных и нормативно-регуяятивных функций и конституционно-правовая ответственность за их выполнение».

А Законом РФ о поправке к Конституции РФ от 14 марта 2020 г. № 1-ФКЗ в ее ст. 114 были дополнительно введены часть е.5, в соответствии с которой Правитедьство РФ осуществляет меры, направленные на создание благоприятных условий жизнедеятельности населения, снижение негативного воздействия хозяйственной и иной деятельности на окружающую среду, сохранение уникального природного и биологического многообразия страны, формирование в обществе ответственного отношения к животным; и часть е.6, в соответствии с которой Правительство РФ создает условия для развития системы экологического образования граждан, воспитания экологической культуры.

Названные поправки 2020 г. к Конституции РФ сами по себе обусловливают необходимость корректировки названных Основ государственной подитики в области экологического развития РФ на период до 2030 г. И этот обновленный подитико-правовой документ органически должен вкдючать в себя механизм блокировки мероприятий (инициатива которых от кого бы то не исходила), направленных на ослабление экологических требований и иных мер отказа (приостановления) озеленения экономики в период природных и техногенных катастроф типа коронавирусной пандемии 2020 $\Gamma$.

А далее, уже в сфере соответствующего сугубо правового регулирования экологических отношений и отношений в сфере «зеленой экономики», провести адекватную корректировку ряда законодательных и иных нормативных правовых актов, в качестве первого шага которой можно посчитать уже принятый Федеральный закон от 13 июля 2020 г. № 207-Ф3 «О внесении изменений в статью 46 Федерального закона «Об охране окружающей среды» и отдельные законодательные акты Российской Федерации» ${ }^{18}$.

Вместе с тем очевидно, что совершенствование нормативно-правового регулирования в сфере «зелёной» экономики, тем более с учётом «опыта» коронавирусной пандемии, требует предварительной серьёзной научной проработки. Такой проработки, в частности, требует широко будируемая идея введения «зелёных сертификатов» - электронных документов, которые предполагается выдавать по факту производства электроэнергии на низкоуглеродных генерирующих объектах, использующих возобновляемые источники энергии. Предполагается, что таким сертификатом будут удостоверяться права, обусловленные совокупностью позитивных - с точки зрения охраны окружающей среды - факторов, сопровождающих производство электроэнергии: снижение уровня экологического вреда, в целом - снижение уровня негативного антропогенного воздействия на окружающую среду и, прежде всего, на здоровье человека; повышение качества жизни человека и т.д. ${ }^{19}$ Но в реалии такой позитивный посыл может привести к утере конкурентных преимуществ нашей энергетики - ведь иностранные производители электроэнергии не будут ограничены нашими «зелёными сертификатами». Здесь требуется глубокая научно-правовая проработка проблемы в международно-правовом аспекте.

\section{Пристатейный библиографический список}

1. Высторобец Е.А. Экологизация судебных споров, касающихся подьзования радиочастотными природными ресурсами // Российское правосудие. 2015. № 6 (110). С. 110.

2. Жизнин С., Черечукин А. Новый этап конкуренции энергоносителей. Неизбежность перехода на зеленые технологии не исключает использование твердого ископаемого топдива // Независимая газета энергия. 2020, 9 июня.

3. Мельников В.Ю. Российское законодательство в период пандемии коронавирусной инфекции COVID-19 // Российский судья. 2020. № 8. C. 12-18

4. Мохов А.А. Ограничение прав юридических лиц и индивидуальных предпринимателей при чрезвычайных ситуациях // Юрист. 2013. № 6. С. 3-7.

5. Мохов А.А. О концепции правового регулирования экономической деятельности в условиях особых правовых режимов: постановка проблемы // Юрист. 2014. № 4. C. 21-24.

6. Никифоров О. Альтернативные источники энергии в постпандемический период. Перспективы развития ВИЭ в России: мнение производителей //Независимая газета - энергия. 2020, 9 июня.

7. Определение № 304-ЭС20-737 по делу А-75-474/2019 от 23 июля 2020 г.

8. Официальный интернет-портал правовой информации. [Электронный ресурс]. - Режим доступа: http:/pravo.gov.ru. 20.04.2017 г.

9. Официальный сайт Евразийского экономического союза. [Электронный ресурс]. - Режим доступа: http://www.eaeunion.org. 16.04.2020 г.

10. Романовский Г.Б. 2019-nCoV как гибридная угроза системе прав человека // Конституционное и муниципальное право. 2020. № 7.

11. Право и экономическая деятельность: современные вызовы: Монография / Отв. ред. А.В. Габов. М.: «ИЗиСП», «Статут», 2015.

12. Российская газета. 2020, 16 июля.

13. Соловьева О. Коронавирус спровоцировал новый инвестиционный спад // Независимая газета. 2020, 24 августа.

14. Тихонов С. Холодный расчет // Российская газета. 2020, 2 сентября.

15. Российская газета. 2020, 3 апреля.

16. Уразова И. Субсидии украсили зеленым // Коммерсант. 2020, 13 августа.

17. Фролова Е.Е. Зеленые облигации в странах Северной Европы: особенности развития и правового регулирования // Журнал Белорусского государственного университета. Право. 2020. № 2. С. 43-48.

18. Черногор Н.Н., Залоило М.В. Метаморфозы права и вызовы юридической науке в условиях пандемии коронавируса // Журнал российского права. 2020. № 7.

19. Чуличкова Е.В. Конституционно-правовой механизм обеспечения права каждого на благоприятную окружающую среду в Российской Федерации. Автореф. ... канд. юрид. наук. - Екатеринбург, 2018 г. (научный рук-ль - проф. А.Н. Кокотов, судья Конституционного Суда РФ).

18 См.: Российская газета. 2020, 16 июля.

19 Фролова Е.Е. Зеленые облигации в странах Северной Европы: особенности развития и правового регулирования // Журнал Белорусского государственного университета. Право. 2020. № 2. С. 43-48. 